\title{
An unusual case of CD5 negative Mantle cell lymphoma presenting with IgM monoclonal gammopathy
}

\author{
Birgul Onec $^{1}$ (D) $\cdot$ Murat Oktay $^{2} \cdot$ Harika Okutan $^{3} \cdot$ Murat Albayrak $^{3} \cdot{\text { Okan } \text { Yayar }^{3}}^{3}$
}

Received: 22 May 2016 / Accepted: 22 August 2016/Published online: 27 August 2016

(C) Springer-Verlag Berlin Heidelberg 2016

To the editor,

Mantle cell lymphoma (MCL) accounts for 3-10\% of all nonHodgkin's lymphomas (NHL) and is clinically characterized by involvement of the lymph nodes, spleen, blood, and bone marrow. Survival mostly depends on risk factors and ranges from 29 months to 5 years [1]. The characteristic immunophenotype of MCL includes coexpression of B-cell markers, CD5, and absence of CD23, whereas the translocation $\mathrm{t}(11 ; 14)(\mathrm{q} 13 ; \mathrm{q} 32)$ confirms the diagnosis. IgM paraproteinemia is typical for lymphoplasmacytic lymphoma/Waldenström macroglobulinemia (LPL/WM) but can rarely accompany different lymphoma subtypes. Among all lymphomas presented with IgM paraproteinemia, MCL is reported at only about $2.8 \%[2,3]$ so may be difficult to diagnose especially in rare CD5/CD10 immunoprofiles. Here, we report an unusual CD5 negative MCL case with clinical features of IgM paraproteinemia.

A 57-year-old male patient was admitted to our clinic with lymphadenopathy (LAP) on both sides of the neck and inguinal regions. He described the painless swelling of lymph nodes for the previous 3 months. Physical examination revealed bilateral multiple cervical, supraclavicular, axillary, and inguinal LAPs of maximum $3.5 \times 2.5 \mathrm{~cm}$ size and splenomegaly palpable as $2 \mathrm{~cm}$. Laboratory investigations revealed a relative lymphocytosis $(5900 \mu \mathrm{L}, 65.2 \%)$ with mature small-

Birgul Onec

birgulonec@gmail.com

1 Department of Hematology, Duzce University Faculty of Medicine, Konuralp, 81000 Duzce, Turkey

2 Department of Pathology, Duzce University Faculty of Medicine, Duzce, Turkey

3 Department of Hematology, Dıșkapı Y Yldırım Beyazıt Education and Research Hospital, Ankara, Turkey to medium-sized lymphocytes observed at about $65 \%$ at peripheral blood smear. Biochemical parameters were normal, including LDH and uric acid. Serum protein electrophoresis revealed a low amplitude monoclonal peak that serum immunofixation electrophoresis defined as IgG lambda monoclonal gammopathy of $2.16 \mathrm{~g} / \mathrm{L}$ (normal range $0.4-2.3 \mathrm{~g} / \mathrm{L}$ ). Bone marrow biopsy showed mature small- to medium-sized lymphoid cells that were positive with CD20, bcl-2, and negative with CD56, CD10, bcl-6, CD5, and CD23. Nuclear cyclin D1 (bcl-1) immunoreactivity was also detected in about $60 \%$ of tumor cells (Fig. 1). Scattered interstitial plasma cells were monitored with CD138 but a similar proportion of plasma cells were positive with the kappa and lambda straining. Presentation with IgM paraproteinemia and immunophenotype of lymphoid cells was consistent with LPL/WM but morphologic features were not with the absence of plasmoid cells. Excisional biopsy of inguinal LAP showed diffuse and nodular infiltration of small atypical lymphoid cells with similar immunophenotype (CD20, Bcl-2, nuclear cyclin D1 positive and CD3, CD5, CD10, CD21, CD23, CD43, Bcl-6 negative with $\mathrm{Ki}-67$ proliferation index of $60 \%$ ). In order to clarify the diagnosis, flow-cytometric (FCM) and $\mathrm{t}(11,14)(\mathrm{q} 31 ; \mathrm{q} 32)$ fluorescence in situ hybridization (FISH) analysis were performed. The same distinct immunoprofile and $\mathrm{t}(11,14)$ positivity confirmed diagnosis of MCL. Because the patient did not accept a new biopsy, he was evaluated with radiological findings, peripheral blood smear, and peripheral FISH for $\mathrm{t}(11,14)$ after six courses of R-CHOP (rituximab, cyclophosphamide, doxorubicin, vincristine, and prednisolone) and was considered as complete remission (CR).

Mantle cell lymphoma is defined as an aggressive and distinct lymphoma subtype characterized by the $\mathrm{t}(11 ; 14)(\mathrm{q} 13 ; \mathrm{q} 32)$ translocation, which results in overexpression of Cyclin D1 [4]. Some degree of bone marrow involvement can be detected in nearly all cases by flow cytometry [1]. Its characteristic 


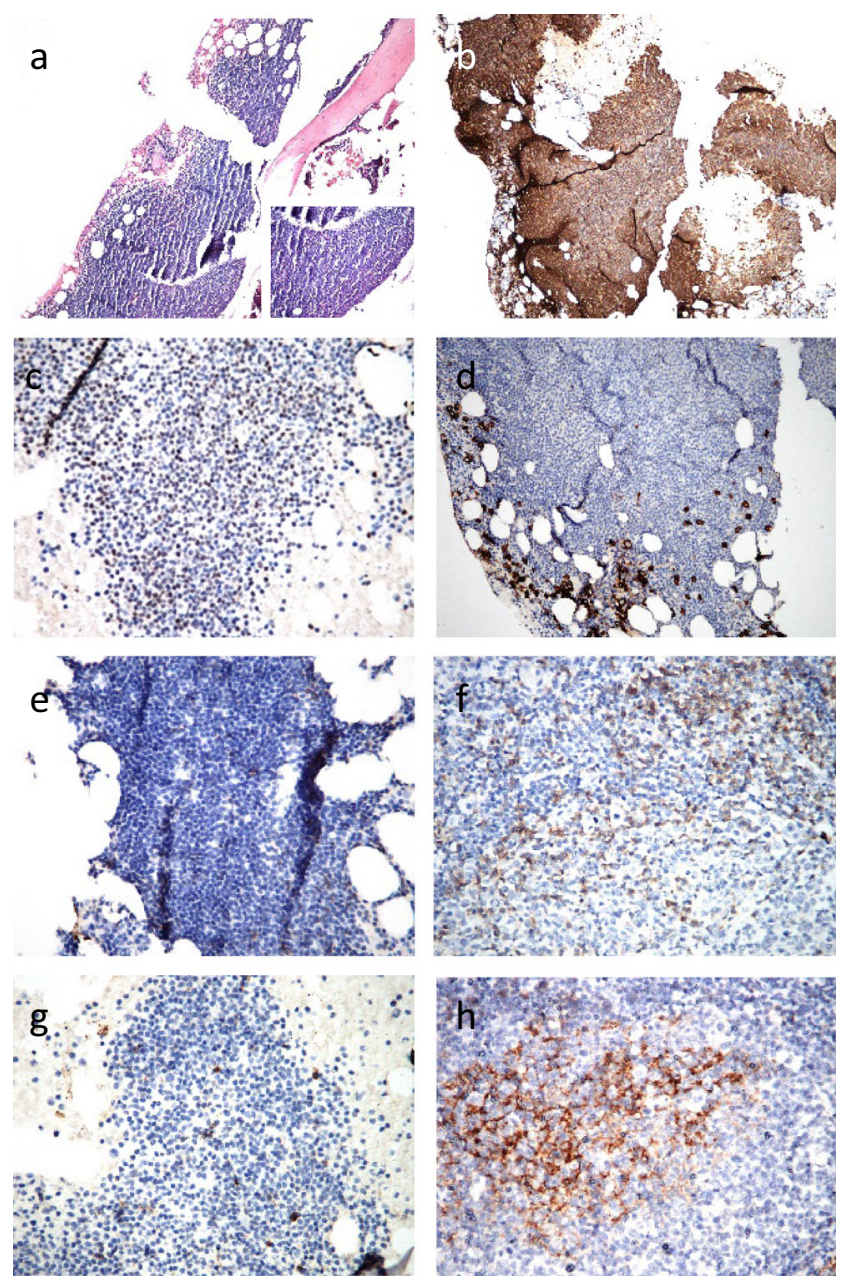

Fig. 1 a Nodular lymphocyte accumulation fitting trabecula of bone marrow (h\&e $\times 100)$ inset. Accumulation of small- to medium-sized lymphocytes with notched nuclei, 400. b Widespread anti-CD20 cytoplasmic immunoreactivity in nodular tumor. c Nuclear cyclin d1 (bcl 1) immunoreactivity at $60 \%$ of the tumor cells. d CD138 positive plasma cells, which were polyclonal in kappa and lambda straining scattered around $\mathbf{e} \mathrm{CD} 5, \mathbf{f}$ control for CD5, $\mathbf{g}$ CD23, $\mathbf{h}$ control for CD23

immunophenotype includes coexpression of B-cell markers, CD5, and FMC-7 and absence of CD23, whereas the translocation $\mathrm{t}(11 ; 14)(\mathrm{q} 13 ; \mathrm{q} 32)$ confirms the diagnosis [5]. This confirmation becomes important especially in unusual presentations such as our case because morphologic and immunophenotypic heterogeneity (CD5-, CD23+ or CD5-, CD23- cases) exists [6].

IgM paraproteinemia is typical for LPL/WM, which consists of small B lymphocytes with variable plasmacytoid differentiation that are usually negative for CD5, CD10, and CD23. IgM paraprotein can rarely accompany different lymphoma subtypes, mostly chronic lymphocytic leukemia/small lymphocytic lymphoma (CLL/SLL), marginal zone lymphoma (MZL), and follicular lymphoma (FL) whereas it is an unusual feature for MCL [7]. In a study that investigated 382 consecutive IgM paraproteinemia-related lymphoid neoplasms, authors reported only $11(2.88 \%)$ MCL cases [2] all of which were $\mathrm{CD} 5(+), \mathrm{CD} 23(-)$, cyclin D1 (+), or carried the $\mathrm{t}(11 ; 14)$. Owen et al. described a similar frequency $(n=3$, $2.83 \%$ ) in a series containing 106 patients [3]. The serum IgM paraprotein levels in MCL were reported lower than in LPL/WM with a median of $0.4 \mathrm{~g} / \mathrm{dL}$ [2], as in our case.

There are few studies that suggest prolonged survival in CD5 negative MCL cases compared to the $\mathrm{CD} 5$ positive cases $[8,9]$ but it is very hard to ascertain the true survival data given the rarity of this disease subset. We think that the major problem in these cases presenting with exceptional immunophenotype and clinical course is reaching diagnosis. Clinicians should remember that MCL has the worst longterm survival among all B-cell NHLs and the strongest confirmation of a suspected MCL is identification of $t(11 ; 14)$ by cytogenetic or FISH techniques.

\section{Compliance with ethical standards}

Disclosure The authors declare that they have no conflict of interest.

Informed consent Informed consent was obtained from the patient included in the letter.

\section{References}

1. Vose JM (2015) Mantle cell lymphoma: 2015 update on diagnosis, risk-stratification, and clinical management. Am J Hematol 90(8): 739-745. doi:10.1002/ajh.24094

2. Lin P, Hao S, Handy BC, Bueso-Ramos CE, Medeiros LJ (2005) Lymphoid neoplasms associated with IgM paraprotein: a study of 382 patients. Am J Clin Pathol 123(2):200-205

3. Owen RG, Parapia LA, Higginson J, Misbah SA, Child JA, Morgan GJ, Jack AS (2000) Clinicopathological correlates of IgM paraproteinemias. Clin Lymphoma 1(1):39-43, discussion 44-5

4. Swerdlow SH, Campo E, Harris NL, Jaffe ES, Pileri SA, Stein H, Thiele J, Vardiman JW (2008) World Health Organization classification of tumors of haematopoietic and lymphoid tissues. IARC press, Lyon

5. Sriganeshan V, Blom TR, Weissmann DJ (2008) A unique case of mantle cell lymphoma with an aberrant CD5-/CD10+ immunophenotype and typical morphology. Arch Pathol Lab Med 132(8):1346-1349. doi:10.1043/1543-2165(2008)132[1346:aucomc]2.0.co;2

6. Pangalis GA, Kyrtsonis MC, Kontopidou FN, Siakantaris MP, Dimopoulou MN, Vassilakopoulos TP, Tzenou T, Kokoris S, Dimitriadou E, Kalpadakis C, Tsalimalma K, Tsaftaridis P, Panayiotidis P, Angelopoulou MK (2005) Differential diagnosis of Waldenstrom's macroglobulinemia and other B-cell disorders. Clin Lymphoma 5(4):235-240

7. Rymkiewicz G, Gos M, Blachnio K, Woroniecka R, Swoboda P, Pienkowska-Grela B, Kulinska M, Borawska A, Janik P, Walewski J (2005) Mantle cell lymphoma presenting with paraproteinemia. Med Oncol (Northwood, London, England) 22(3):319-323. doi:10.1385/mo:22:3:319

8. Alvarez-Argote J, Bauer FA, Dasanu CA (2014) CD5 negative mantle cell lymphoma: a different clinical entity? Conn Med 78(4):211-214

9. Yamada T, Goto N, Tsurumi H, Takata K, Sato Y, Yoshino T, Moriwaki H, Kito Y, Takeuchi T, Iwata H (2014) Mantle cell lymphoma with a unique pattern of CD5 expression: a case report with review of the literatures. Med Mol Morphol 47(3):169-175. doi:10.1007/s00795-013-0060-x 